\title{
Insomnia is more common among subjects living in damp buildings
}

\section{Janson, D Norbäck, E Omenaas, T Gislason, L Nyström, R Jõgi, E Lindberg, M Gunnbjörnsdottir, E Norrman, T Wentzel-Larsen, C Svanes, E J Jensen, K Torén, on behalf of the RHINE study group}

See end of article for authors' affiliations

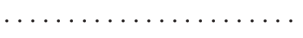

Correspondence to: Dr C Janson, Department of Medical Sciences: Respiratory Medicine and Allergology, Akademiska sjukhuset, SE 75185 Uppsala, Sweden; christer. janson@medsci.uu.se

Accepted 10 July 2004
Background: Insomnia is a condition with a high prevalence and a great impact on quality of life. Little is known about the relation between and sleep disturbances and the home environment.

Aim: To analyse the association between insomnia and building dampness.

Methods: In a cross-sectional, multicentre, population study, 16190 subjects (mean age 40 years, 53\% women) were studied from Reykjavik in Iceland, Bergen in Norway, Umeå, Uppsala, and Göteborg in Sweden, Aarhus in Denmark, and Tartu in Estonia. Symptoms related to insomnia were assessed by questionnaire.

Results: Subjects living in houses with reported signs of building dampness ( $n=2873$ ) had a higher prevalence of insomnia $(29.4$ v $23.6 \%$; crude odds ratio $1.35,95 \% \mathrm{Cl} 1.23$ to 1.48$)$. The association between insomnia and different indicators of building dampness was strongest for floor dampness: "bubbles or discoloration on plastic floor covering or discoloration of parquet floor" (crude odds ratio $1.96,95 \% \mathrm{Cl} 1.66$ to 2.32 ). The associations remained significant after adjusting for possible confounders such as sex, age, smoking history, housing, body mass index, and respiratory diseases. There was no significant difference between the centres in the association between insomnia and building dampness. Conclusion: Insomnia is more common in subjects living in damp buildings. This indicates that avoiding dampness in building constructions and improving ventilation in homes may possibly have a positive effect on the quality of sleep.
! nsomnia is a condition with a high prevalence ${ }^{1-3}$ and a great impact on quality of life. ${ }^{4}$ Previous studies have shown that insomnia is related to lifestyle factors such as smoking and excessive use of alcohol, ${ }^{25}{ }^{6}$ as well as somatic and psychiatric disorders. ${ }^{2-9}$ In medical textbooks it is recommended that the bedrooms should be well ventilated and have a comfortable temperature, ${ }^{10}$ but scientific investigations on the relation between the home environment and sleep disturbances are lacking. This is somewhat surprising since most people sleep eight hours at night, which is a large part of the time spent at home.

Several studies have found that living in a home with mould or water damage increases the risk of respiratory symptoms such as wheeze, asthma, and mucosal irritation of the upper airways. ${ }^{11-14}$ An association between sleep disturbances and building dampness has, however, to our knowledge only been reported in one previous study. ${ }^{15}$

The aim of this study was to analyse the association between insomnia and indicators of building dampness in population based samples in the Nordic countries.

\section{METHODS}

This is a cross-sectional analysis of a follow up study.

\section{Population}

The Respiratory Health in Northern Europe (RHINE) is a follow up study of participants from seven Northern European centres who participated in the European Community Respiratory Health Survey (ECRHS) stage 1, in 1990-94. ${ }^{16}$ In stage 1 of the ECRHS, men and women, aged 20-44 years, were randomly selected from the population registers of each participating centre. A postal questionnaire was sent to 3000-4000 subjects in each centre. The target population for the RHINE study was all subjects from
Reykjavik in Iceland, Bergen in Norway, Umeå, Uppsala, and Göteborg in Sweden, Aarhus in Denmark, and Tartu in Estonia that participated in stage 1 of the ECRHS $(\mathrm{n}=21802$, response rate $83.7 \%)$. The eligible subjects were sent a postal questionnaire in 1999-2001. Two reminders were sent to subjects not responding to the first mailing. In total $16190(74.2 \%)$ subjects answered the questionnaire. The informed consent of all participants was obtained and the study was approved by all the local ethics committees.

\section{Questionnaire}

The first part of the questionnaire contained 12 questions identical to those asked in the ECRHS stage 1, including questions on respiratory symptoms, asthma, rhinitis, and gender. The second part contained 52 questions covering various aspects such as bronchitis, smoking, indoor environment, and sleep disorders. The seven questions on sleep disorders were derived from the Basic Nordic Sleep Questionnaire. ${ }^{17}$ The questions have previously been used in four of the ECRHS centres ${ }^{118}$ and have been published as an appendix in a previous report. ${ }^{1}$ The subjects were asked to estimate the frequency of different symptoms during the last months on a five point scale: 1 , never; 2 , less than once a week; 3, 1-2 nights per week; 4, 3-5 nights per week; and 5, almost every night.

\section{Insomnia}

The three aspects of insomnia analysed in this investigation were difficulty inducing sleep (DIS), difficulty maintaining sleep (DMS), and early morning awakenings (EMA). DIS was defined as "difficulty in falling asleep at night", DMS as "waking up repeatedly during the night", and EMA as "waking up too early and having difficulty in getting to sleep again". For all three symptoms a frequency of at least three nights per week 


\section{Main messages}

- The prevalence of insomnia is higher in subjects living in homes with building dampness.

- This association remains after adjusting for possible confounders such as smoking, respiratory diseases, and type of housing.

was used as the cut off point. Insomnia was defined as reporting at least one of the three symptoms defined above.

\section{Home environment}

The questions on building characteristics have been used in several previous investigations ${ }^{11}{ }^{14}$ and have been validated against direct observations by an occupational hygienist. ${ }^{11}$ Water damage was defined as having observed "water leakage or water damage indoors in walls, floors, or ceilings". Visible moulds was defined as having observed "visible mould growth indoors on walls, floors, or ceilings". Floor dampness was defined as having observed "bubbles or yellow discoloration on plastic floor covering, or black discoloration of parquet floor". Building dampness was defined as reporting at least one of the three indicators defined above. The recall period was 12 months. In addition the subjects were asked to specify type and age of housing.

\section{Socioeconomic index}

A socioeconomic index was created using information on current occupation in four of the seven centres (Bergen, Göteborg, Uppsala, and Tartu). Based on this information the subjects were divided in to the following categories:

I. "Managers and professionals; non-manual" (legislators, senior officials, managers, and professional)

II. "Other non-manual" (technicians and associate professionals, clerks, service workers, and market sales workers)

III. "Skilled manual" (skilled agricultural and fishery workers and craft and related trades workers)

IV. "Semi-skilled or unskilled manual" (plant and machine operators and assemblers and elementary occupations)

V. "Unclassifiable or unknown" (housewife, student, not classifiable job, unemployed, not working because of poor health and retired).

\section{Policy implication}

- Avoiding dampness in building constructions and improving ventilation in homes may have a positive effect on the quality of sleep.

\section{Other explanatory variables}

Smoking history was assessed by two questions: "Are you a smoker (this applies even if you only smoke the odd cigarette/ cigar or pipe every week)?" and "Are you an ex-smoker?". The subjects were categorised into three groups: never smokers, ex-smokers, or current smokers.

Body mass index (BMI) was calculated from the subjects' self-reported height and weight: (weight in $\mathrm{kg}) \times($ height in metres) $)^{-2}$.

Asthma was defined as a positive answer to both of the questions: "Do you have or have you ever had asthma?" and "Have you ever had asthma diagnosed by a doctor?".

Allergic rhinitis was defined as a positive answer to the question: "Do you have any nasal allergies including hay fever?".

Chronic bronchitis was defined as a negative answer to both asthma questions above and positive answers to all three of the following questions: "Do you usually bring up phlegm or do you have phlegm in your airways which you have difficulty bringing up?", "Do you bring up phlegm in this way almost daily at least three months every year?", and "Have you had this kind of problem for at least two years in a row?".

\section{Statistics}

The statistical analysis was performed using Stata 7.0 and 8.0 (Stata Corporation, College Station, Texas). The $\chi^{2}$ test and unadjusted logistic regression were used when comparing subjects with different household conditions in the univariate analyses. To study the influence of different explanatory variables on insomnia, adjusted odds ratios (OR) were calculated by multiple logistic regression. The choice of the non-environmental explanatory variables was based on experience from previous studies of insomnia. ${ }^{12}$ In these analyses the indicators of building dampness were included separately in the analyses. The adjusted OR was analysed on pooled data from all seven centres, adjusting for centre. In order to detect heterogeneity between centres in the relation between insomnia and building dampness, the adjusted OR

Table 1 Characteristics of the study populations and prevalence of insomnia related symptoms

\begin{tabular}{|c|c|c|c|c|c|c|c|c|}
\hline & $\begin{array}{l}\text { Reykjavik } \\
\text { ( } n=1969 \text { ) }\end{array}$ & $\begin{array}{l}\text { Bergen } \\
(n=2506)\end{array}$ & $\begin{array}{l}\text { Umeå } \\
(n=2640)\end{array}$ & $\begin{array}{l}\text { Uppsala } \\
\text { ( } n=2572 \text { ) }\end{array}$ & $\begin{array}{l}\text { Göteborg } \\
\text { ( } n=2188)\end{array}$ & $\begin{array}{l}\text { Aarhus } \\
(n=2607)\end{array}$ & $\begin{array}{l}\text { Tartu } \\
\text { ( } n=1708)\end{array}$ & $\begin{array}{l}\text { All subjects } \\
(\mathrm{n}=16190)\end{array}$ \\
\hline Response rate & 67.8 & 72.6 & 80.2 & 81.8 & 76.0 & 71.0 & 69.4 & 74.2 \\
\hline Age, years & $41(7)$ & $41(7)$ & $41(7)$ & $40(7)$ & $40(7)$ & $39(7)$ & $36(7)$ & $40(7)$ \\
\hline Women & 54.6 & 51.9 & 51.5 & 52.5 & 54.2 & 52.2 & 56.1 & 53.0 \\
\hline Ex-smokers & 31.5 & 24.5 & 26.2 & 26.1 & 25.6 & 34.6 & 17.1 & 25.1 \\
\hline Current smokers & 30.9 & 38.5 & 19.2 & 19.6 & 29.5 & 34.6 & 35.3 & 29.3 \\
\hline Detached house & 28.6 & 49.4 & 57.5 & 42.7 & 34.8 & 47.9 & 25.9 & 42.5 \\
\hline Semi-detached house & 25.7 & 21.1 & 11.3 & 12.8 & 17.3 & 15.3 & 2.6 & 15.3 \\
\hline Apartment & 45.7 & 29.5 & 31.2 & 44.5 & 47.9 & 36.8 & 71.5 & 42.2 \\
\hline $\begin{array}{l}\text { Building dampness (at least one } \\
\text { indicator) }\end{array}$ & 22.7 & 16.4 & 13.9 & 14.6 & 12.1 & 18.8 & 31.6 & 17.9 \\
\hline Water damage & 20.1 & 13.4 & 9.8 & 9.1 & 7.7 & 14.4 & 23.4 & 13.4 \\
\hline Visible moulds & 6.6 & 4.5 & 3.5 & 6.2 & 4.5 & 10.1 & 13.6 & 6.7 \\
\hline Floor dampness & 6.4 & 2.2 & 5.4 & 4.1 & 4.5 & 2.2 & 2.6 & 3.8 \\
\hline Insomnia (at least one symptom) & 25.0 & 22.3 & 26.5 & 24.6 & 32.0 & 21.4 & 22.2 & 24.8 \\
\hline Difficulty inducing sleep & 6.8 & 8.9 & 7.9 & 6.5 & 11.2 & 6.0 & 7.9 & 7.8 \\
\hline Difficulty maintaining sleep & 18.3 & 16.0 & 20.8 & 19.8 & 24.5 & 16.4 & 15.5 & 18.8 \\
\hline Early morning awakenings & 9.5 & 8.2 & 8.6 & 9.1 & 11.2 & 7.4 & 9.2 & 8.9 \\
\hline
\end{tabular}


was calculated separately in each centre. An average effects estimate was derived, and potential heterogeneity between centres was examined using standard methods for random effects meta-analysis. ${ }^{19}$

\section{RESULTS}

Table 1 presents the response rate and characteristics of the subjects of the different centres. The non-responders were somewhat younger ( 31 (7) $v 32$ (7) years of age in the ECRHS I 1990-94; $\mathrm{p}<0.001)$, more often men (54.0 $v$ 46.7\%; $\mathrm{p}<0.001)$, and had at baseline a lower prevalence of allergic rhinitis ( $18.4 \vee 20.8 \%$; p $<0.01$ ) than the responders. In Tartu the age of the subjects at the follow up was significantly lower than in the other centres due to the fact that the ECRHS I was performed some years later in Tartu than the other centres (36 (7) v 40 (7) years, p 0.001). The highest prevalence of all three insomnia related symptoms was found in Göteborg (table 1).

Building dampness was reported by 2873 subjects (17.9\%) in the investigation. Subjects that lived in homes with signs of building dampness were significantly younger, and more often women and current smokers than subjects not reporting building dampness. Subjects that reported building dampness were also more often living in apartments and older buildings than subjects that did not report building dampness (table 2).

Subjects living in homes with dampness had a significantly higher prevalence of insomnia and all three insomnia related symptoms (table 2). A significantly higher prevalence of insomnia was found for all three indicators of building dampness (fig 1). No significant trend was found between building age and the prevalence of insomnia.

Living in homes with signs of building dampness was an independent risk factor of insomnia and insomnia related symptoms even after adjustment for sex, age smoking history, and housing and building age (tables 3 and 4). Other risk factors for insomnia were female gender, being an ex-smoker or current smoker, and living in an apartment (table 3). The risk of insomnia also increased with increasing BMI (OR 1.03, 95\% CI 1.02 to 1.04) and was higher in subjects with allergic rhinitis (OR $1.26,95 \%$ CI 1.15 to 1.39 ), asthma (OR 1.72, 95\% CI 1.50 to 1.98), and chronic bronchitis (OR 2.17, 95\% CI 1.81 to 2.59) than in subjects without these disorders. No significant interaction between insomnia

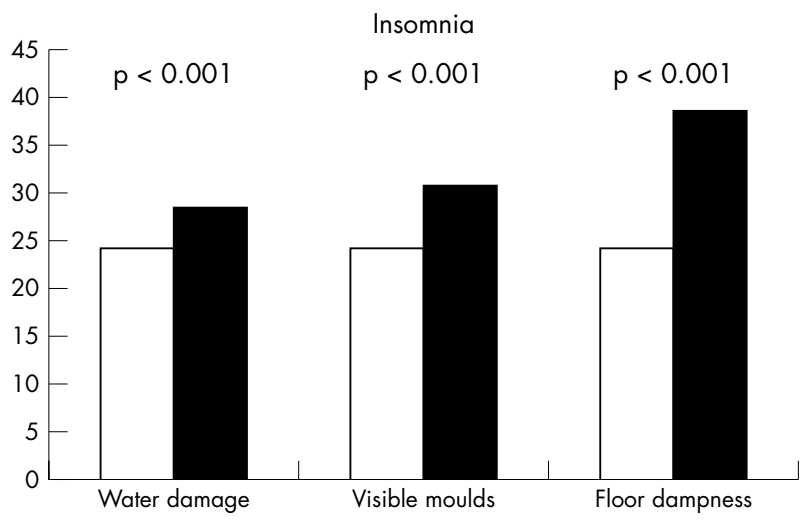

Figure 1 The prevalence of insomnia in subjects living in homes without (open bars) and with (shaded bars) indicators of building dampness.

and building dampness was found in relation to sex, smoking, or type of housing.

The association between insomnia and building dampness remained significant after adjusting for socioeconomic status (OR $1.39,95 \%$ CI 1.21 to 1.60 ) in the subpopulation of 7100 subjects where this information was available.

The association between building dampness and insomnia was assessed by meta-analysis in order to detect heterogeneity between the centres (fig 2). Meta-analyses were also performed for the association of the other indicators of building dampness and insomnia. In all analyses the estimates were almost identical to those derived when analysing the pooled data, and no significant centre heterogeneity was detected $(\mathrm{p}>0.30)$.

\section{DISCUSSION}

The main finding in this analysis is that insomnia related symptoms were more common in subjects living in houses with building dampness. This relation remained significant after adjusting for other possible confounders such as smoking, type of housing, and respiratory disorders.

The association between insomnia and building dampness is a novel finding which may be of large importance from a public health perspective given the high prevalence and

Table 2 Characteristics of the study populations and prevalence of insomnia related symptoms in relation to reported building dampness

\begin{tabular}{|c|c|c|c|}
\hline & $\begin{array}{l}\text { No building dampness } \\
(\mathrm{n}=13154)\end{array}$ & $\begin{array}{l}\text { Building dampness } \\
\text { ( } \mathrm{n}=2872 \text { ) }\end{array}$ & p value \\
\hline Age, years & $40.1(7.3)$ & $38.5(7.2)$ & $<0.001$ \\
\hline Women & 52.2 & 57.0 & $<0.001$ \\
\hline Smoking history & & & $<0.001$ \\
\hline Never smokers & 46.3 & 42.9 & \\
\hline Ex-smokers & 25.1 & 25.2 & \\
\hline Current smokers & 28.6 & 31.9 & $<0.001$ \\
\hline Type of housing & & & $<0.001$ \\
\hline Detached house & 44.2 & 35.2 & \\
\hline Semi-detached house & 15.6 & 14.4 & \\
\hline Apartment & 40.3 & 50.4 & \\
\hline Age of housing & & & $<0.001$ \\
\hline $0-10$ years & 14.2 & 9.0 & \\
\hline $11-20$ years & 20.0 & 17.5 & \\
\hline $21-40$ years & 33.6 & 35.8 & \\
\hline $41-60$ years & 15.4 & 17.0 & \\
\hline More than 60 years & 16.7 & 20.7 & \\
\hline Insomnia (at least one symptom) & 23.6 & 29.4 & $<0.001$ \\
\hline Difficulty inducing sleep & 7.3 & 10.0 & $<0.001$ \\
\hline Difficulty maintaining sleep & 17.8 & 22.4 & $<0.001$ \\
\hline Early morning awakenings & 8.6 & 10.4 & 0.002 \\
\hline
\end{tabular}


Table 3 Association between insomnia and indicators of building dampness

\begin{tabular}{|c|c|c|}
\hline & \multicolumn{2}{|c|}{ Insomnia (at least one symptom) } \\
\hline & $\begin{array}{l}\text { Crude OR }(95 \% \mathrm{Cl}) \\
(\mathrm{n}=15785)\end{array}$ & $\begin{array}{l}\text { Adjusted OR }(95 \% \mathrm{Cl})^{*} \\
(\mathrm{n}=14034)\end{array}$ \\
\hline Women & $1.36(1.27$ to 1.46$)$ & $1.43(1.31$ to 1.55$)$ \\
\hline Never smoker & 1 & 1 \\
\hline Ex-smoker & 1.30 (1.19 to 1.42$)$ & $1.21(1.10$ to 1.34$)$ \\
\hline Current smoker & 1.27 (1.17 to 1.39$)$ & $1.13(1.03$ to 1.25$)$ \\
\hline Detached house & 1 & 1 \\
\hline Semi-detached & $1.03(0.92$ to 1.15$)$ & 1.00 (0.88 to 1.13$)$ \\
\hline Apartment & 1.25 (1.15 to 1.35$)$ & $1.25(1.14$ to 1.36$)$ \\
\hline Building dampness (at least one indicator)† & 1.35 (1.23 to 1.48$)$ & $1.33(1.21$ to 1.48$)$ \\
\hline Water damage & 1.25 (1.13 to 1.39$)$ & $1.26(1.12$ to 1.41$)$ \\
\hline Visible moulds & 1.38 (1.21 to 1.58$)$ & $1.33(1.14$ to 1.36$)$ \\
\hline Floor dampness & 1.96 (1.66 to 2.32$)$ & $1.74(1.44$ to 2.10$)$ \\
\hline \multicolumn{3}{|c|}{$\begin{array}{l}\text { Result are presented as crude and adjusted odds ratios ( } 95 \% \mathrm{CI}) \text {. } \\
{ }^{*} \text { Adjusted for centre, age, building age, body mass index, allergic rhinitis, asthma, chronic bronchitis, and the } \\
\text { variables in the table. } \\
\text { †Each indicator of building dampness entered separately. }\end{array}$} \\
\hline
\end{tabular}

serious consequences of insomnia. ${ }^{1-4}$ A relation between quality of sleep and building dampness has to our knowledge only been reported in one study. In that investigation Packer and co-workers reported that people living in damp buildings more often complained of perceived ill health, including problems related to poor sleep as measured by the Nottingham Health Profile. ${ }^{15}$

A higher prevalence of insomnia was found in subjects living in apartments compared to those living in detached houses. There are several possible explanations for this finding. The type of housing can be related to social status, and a lower social status has in some reports been related to poorer quality of sleep. ${ }^{2021}$ Night-time problems with disturbing noise from traffic or neighbours are probable more common for subjects living in apartments than in detached houses. It should, however, be noted that there were no significant differences between different types of housing in the association between insomnia related symptoms and building dampness, and that the relation between insomnia and building dampness remained significant after adjusting for

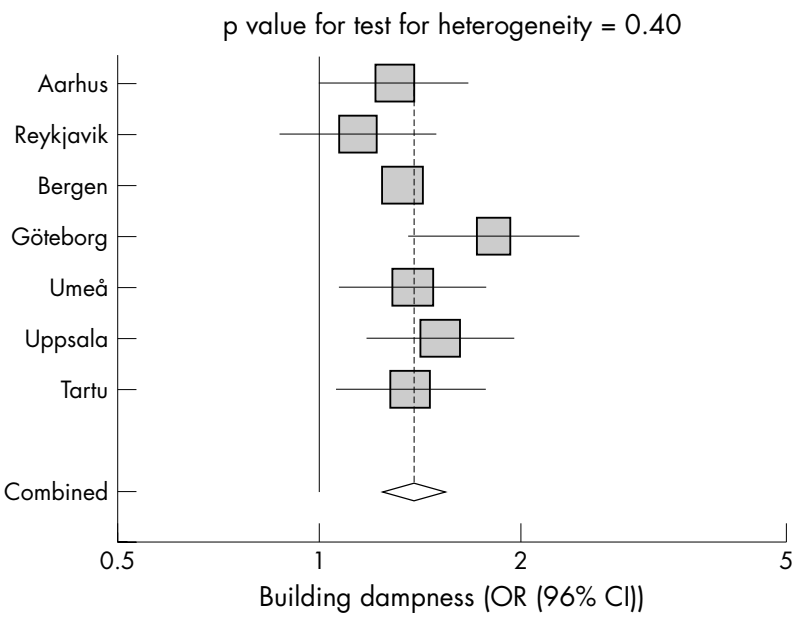

Figure 2 Adjusted odds ratios and $95 \% \mathrm{Cls}$ of insomnia related symptoms at least three nights per week in subjects living in homes with reported building dampness compared to subjects living in homes without building dampness (adjusted within centre for age, sex, smoking history, type of housing, and age of home) with a combined odds ratio (diamond indicates $95 \% \mathrm{Cl}$ ) from the model with centre as the random effect. The size of each square is proportional to the sample size. socioeconomic status. As in several previous studies we found that insomnia related symptoms were more common in women than in men, ${ }^{122-24}$ and more frequent in smokers than non-smokers. ${ }^{125}$

In contrast to the lack of studies on the association between quality of sleep and the indoor environment, there is a large amount of evidence showing a relation between respiratory disorders and building dampness. ${ }^{12}{ }^{13}$ In our analysis the association between insomnia and building dampness remained significant after adjusting for respiratory disorders such as asthma, rhinitis, and chronic bronchitis, indicating that this association can only partially be explained by the known association between building dampness and airway diseases. The relation between insomnia and building dampness also remained significant after adjusting for other indicators of respiratory health, such as wheeze or the number of respiratory infections in the past 12 months (data not shown).

There are different mechanisms that could explain the observed association between insomnia and building dampness. House dust mites thrive in a humid environment. The presence of house dust mite and sensitisation to mites are, however, lower in Northern Europe than in regions with a warmer climate. ${ }^{26}{ }^{27}$ It is therefore less likely that exposure to house dust mites explains the relation between dampness and insomnia in our investigation. Moulds thrive in damp environments, and it has been shown that persisting water damage for more than three days increases the indoor levels of spores. ${ }^{28}$ The major structural components of fungal cell wall are glucans, which can cause respiratory symptoms. ${ }^{29} 30$ Airborne levels of $\beta$-1,3-glucan have also been associated with more general symptoms such as lethargy and fatigue. ${ }^{31}$ Microbial indoor growth may cause an emission of volatile organic compounds (VOC) of microbial origin (MVOC). ${ }^{32}$ Some of these compounds have a typical mouldy or pungent smell. Perception of such odours can increase the awareness of poor indoor air quality, as well as nasal and throat symptoms. ${ }^{14}$ Building dampness may also increase the emission of VOC due to chemical degradation of building material, without microbial growth. One such example is degradation of phthalate esters, used as plasticizers in poly-vinyl-chloride (PVC) floor coatings or glues, causing an emission of the compound 2-etyl-1-hexanol to the indoor air. ${ }^{33}$ Increased emission of VOC and MVOC in damp homes may lead to increased perception of impaired air quality and dryness in mucous membranes, resulting in sensory perceptions impairing sleep quality. In addition, dampness related exposures 
Table 4 Independent association between insomnia related symptoms and indicators of building dampness

\begin{tabular}{llll}
\hline & $\begin{array}{l}\text { Difficulty inducing sleep } \\
\text { OR }(95 \% \mathrm{Cl})^{*}\end{array}$ & $\begin{array}{l}\text { Difficulty maintaining } \\
\text { sleep } \\
\text { OR }(95 \% \mathrm{Cl})^{*}\end{array}$ & $\begin{array}{l}\text { Early morning awakenings } \\
\text { OR }(95 \% \mathrm{Cl})^{*}\end{array}$ \\
\hline $\begin{array}{l}\text { Building dampness (at least } \\
\text { one indicator)t }\end{array}$ & $1.30(1.10$ to 1.52$)$ & $1.33(1.19$ to 1.49$)$ & $1.23(1.06$ to 1.44$)$ \\
$\begin{array}{l}\text { Water damage } \\
\text { Visible moulds }\end{array}$ & $1.24(1.03$ to 1.48$)$ & $1.27(1.12$ to 1.36$)$ & $1.09(0.92$ to 1.30$)$ \\
$\quad$ Floor dampness & $1.33(1.05$ to 1.69$)$ & $1.32(1.11$ to 1.56$)$ & $1.37(1.09$ to 1.70$)$ \\
\hline
\end{tabular}

Results are presented as adjusted odds ratios $(95 \% \mathrm{CI})$.

*Adjusted for centre, age, building age, body mass index, allergic rhinitis, asthma, chronic bronchitis, and the variables in the table.

†Each indicator of building dampness entered separately.

could cause nasal mucosal swelling and inflammation, ${ }^{33-35}$ which in turn could impair sleep quality.

In the present study floor dampness was the dampness indicator that was most closely related to insomnia. This is to some extent in accordance with a previous study where we found that dampness in floor constructions was the dampness indicator with the strongest association to asthma. ${ }^{11}$ Dampness in concrete floor construction is a common phenomenon in modern buildings in Northern Europe and is mainly associated with chemical degradation of building materials, not with mould growth. Increased humidity in the concrete slab causes an alkaline degradation of di-ethylhexylphtalate (DEHP), a plasticizer used in PVC materials, or a degradation of acrylate-polymers in water based floor glues. Both these processes lead to emission of 2-etyl-1-hexanol to the indoor environment. Increased dampness in concrete floors has been associated with nasal and throat symptoms ${ }^{36}$ as well as increases of lysoszymes in the nasal mucosa reflecting increased inflammatory or secretory activity. ${ }^{33}$

An alternative explanation for the relation between insomnia and building dampness could be that subjects with insomnia are more likely to report building dampness. This explanation does, however, seem less likely, since Pirhonen et al found that the relation between respiratory symptoms and reported building dampness remained unchanged after adjusting for possible confounders such as socioeconomic and psychological factors. ${ }^{37}$ Similar results have been obtained from other studies that have compared results obtained from self-reported and observed building dampness. $^{38} 39$ In our study, living in homes with building dampness was associated with a higher prevalence of other insomnia related variables such as smoking and female gender. The relation between building dampness and insomnia related symptoms did, however, remain statistically significant after adjusting for such covariates as female gender, smoking, obesity, type of housing, and respiratory disorders.

This is one of the largest population studies ever conducted to examine the prevalence of insomnia and associated risk factors. The validity of our results is also to some extent strengthened by the fact that there was no significant difference in the association between insomnia and building dampness in the different centres when this was assessed by meta-analyses. There are, however, several problems that should be taken into account when interpreting the results. The main problem is that the results are based on selfreported data. While it would have been difficult to perform such a large study with actual sleep recordings and home environment monitoring, our results should be confirmed with objective outcome measures. The second problem is related to the fact that this is a cross-sectional analysis of a follow up study. This means that even though the response rate was reasonably high in both stages, our results are based on only $60 \%$ of the original population. The response rate analysis from the present and our previous ECRHS survey has shown that men and younger subjects are slightly underrepresented..$^{40}$ As the absolute differences between nonresponders and responders were relatively small, we do not think that this has affected our results substantially.

In conclusion, we found that insomnia related symptoms were more common in subjects living in damp buildings. This indicates that avoiding dampness in building constructions and improving ventilation in the homes may, in addition to improving respiratory health, also have a positive effect on quality of sleep.

\section{ACKNOWLEDGEMENTS}

The study was supported financially by the Icelandic Research Council, the Swedish Heart and Lung Foundation, the Vårdal Foundation for Health Care Science and Allergy Research, the Swedish Association Against Asthma and Allergy, the Swedish Council for Work Life and Social Research, the Norwegian Research Council project 135773/330, the Norwegian Asthma and Allergy Association, the Danish Lung Association, and the Estonian Science Foundation grant no. 4350 .

\section{Authors' affiliations}

C Janson, E Lindberg, M Gunnbjörnsdottir, Department of Medical Sciences: Respiratory Medicine and Allergology, Uppsala University, Uppsala, Sweden

D Norbäck, Department of Medical Sciences: Occupational and Environmental Medicine, Uppsala University, Uppsala, Sweden E Omenaas, T Wentzel-Larsen, C Svanes, Department of Thoracic Medicine and Centre for Clinical Research, Haukeland University Hospital, Bergen, Norway

T Gislason, Department of Pulmonary Medicine, Landspitali University Hospital, Reykjavik, Iceland

L Nyström, Department of Clinical Medicine and Public Health, Umeå University, Umeå, Sweden

R Jõgi, Foundation Tartu University Clinics, Lung Clinic, Tartu, Estonia E Norrman, Department of Respiratory Medicine and Allergology, University Hospital of Northern Sweden, Umea, Sweden

E J Jensen, Department of Respiratory Diseases, University Hospital of Aarhus, Aarhus, Denmark

K Torén, Section of Occupational and Environmental medicine and Section of Allergology, Sahlgrenska University Hospital, Göteborg, Sweden

The RHINE study group includes the following participants: E J Jensen (Aarhus); A Gulsvik, B N Laerum, E Omenaas, C Svanes (Bergen); A-C Olin, K Torén, A Tunsäter, L Lillienberg (Göteborg); E Biörnsson, $T$ Gislason, D Gislason, T Blöndal, U S Björnsdottir, (Reykjavik); Rain Jõgi, Jana Talvik (Tartu), Bertil Forsberg, K A Franklin, B Lundbäck, E Norrman, M Söderberg, M-C Ledin (Umeå); G Boman, María Gunnbjörnsdottir, C Janson, E Lindberg, D Norbäck, G Wieslander, U Spetz-Nyström, K Stenudd Cashelunge, E Rydén (Uppsala)

\section{REFERENCES}

1 Janson C, Gislason T, De Backer W, et al. Prevalence of sleep disturbances among young adults in three European countries. Sleep 1995;18:589-97. 
2 Janson C, Lindberg E, Gislason T, et al. Insomnia in men-a 10-year prospective population based study. Sleep $2001 ; 24: 425-30$

3 Ohayon MM, Partinen M. Insomnia and global sleep dissatisfaction in Finland. J Sleep Res 2002;11:339-46.

4 Roth T, Ancoli-Israel S. Daytime consequences and correlates of insomnia in the United States: results of the 1991 National Sleep Foundation Survey. II. Sleep, 1999;22, (suppl. 2):S354-8

5 Tachibana H, Izumi T, Honda S, et al. The prevalence and pattern of insomnia in Japanese industrial workers: relationship between psychosocial stress and type of insomnia. Psychiatry Clin Neurosci 1998;52:397-402.

6 Harma M, Tenkanen L, Sjöblom T, et al. Combined effects of shift work and life-style on the prevalence of insomnia, sleep deprivation and daytime sleepiness. Scand J Work Environ Health 1998;24:300-7.

7 Gislason T, Almqvist M. Somatic diseases and sleep complaints. An epidemiological study of 3,201 Swedish men. Acta Med Scand 1987;221:475-81.

8 Dodge R, Cline MG, Quan SF. The natural history of insomnia and its relationship to respiratory symptoms. Arch Intern Med 1995;155:1797-800.

9 Morgan K, Clarke D. Risk factors for late-life insomnia in a representative general practice sample. Br J Gen Pract 1997;47:166-9.

10 Vincent P, Zarcone Jr. Sleep hygiene. In: Kryger MH, Roth T, Dement WC, eds. Principles and practice of sleep medicine. Philadelphia, London: WB Saunders, 2000:657-61.

11 Norbäck D, Björnsson E, Janson C, et al. Current asthma and biochemical signs of inflammation in relation to building dampness in dwellings. Int J Tuberc Lung Dis 1999;3:368-76.

12 Peat JK, Dickerson J, Li J. Effects of damp and mould in the home on respiratory health: a review of the literature. Allergy 1998;53:120-8.

13 Bornehag CG, Blomquist G, Gyntelberg F, et al. Dampness in buildings and health. Nordic interdisciplinary review of the scientific evidence on associations between exposure to "dampness" in buildings and health effects (NORDDAMP). Indoor Air 2001;11:72-86.

14 Engvall K, Norrby C, Norbäck D. Sick building syndrome in relation to building dampness in multi-family residential buildings in Stockholm. Int Arch Occup Environ Health $2001 ; 74: 270-8$.

15 Packer CN, Stewart-Brown S, Fowle SE. Damp housing and adult health: results from a lifestyle study in Worcester, England. J Epidemiol Community Health 1994:48:555-9.

16 Burney PG, Luczynska C, Chinn S, et al. The European Community Respiratory Health Survey. Eur Respir J 1994;7:954-60.

17 Partinen M, Gislason T. Basic Nordic Sleep Questionnaire (BNSQ): a quantitated measure of subjective sleep complaints. J Sleep Res 1995:4:150-5

18 Janson C, Gislason T, De Backer W, et al. Daytime sleepiness, snoring and gastro-oesophageal reflux amongst young adults in three European countries. J Intern Med 1995;237:277-85.

19 DerSimonian R, Laird N. Meta-analysis in clinical trials. Control Clin Trials 1986;7:177-88.

20 Hunt SM, McEwen J, McKenna SP. Social inequalities and perceived health Eff Health Care 1985;2:151-60.

21 Van Cauter E, Spiegel K. Sleep as a mediator of the relationship between socioeconomic status and health: a hypothesis. Ann N Y Acad Sci 1999;896:254-61.
22 Klink ME, Quan SF, Kaltenborn WT, et al. Risk factors associated with complaints of insomnia in a general adult population. Influence of previous complaints of insomnia. Arch Intern Med 1992;152:1634-7.

23 Reyner LA, Horne JA, Reyner A. Gender- and age-related differences in sleep determined by home-recorded sleep logs and actimetry from 400 adults. Sleep 1995; 18:127-34.

24 Lindberg E, Janson C, Gislason T, et al. Sleep disturbances in a young adult population: can gender differences be explained by differences in psychological status? Sleep 1997;20:381-7.

25 Townsend J, Wilkes $\mathrm{H}$, Haines $\mathrm{A}$, et al. Adolescent smokers seen in general practice: health, lifestyle, physical measurements, and response to antismoking advice. BMJ 1991;303:947-50.

26 Björnsson E, Norbäck D, Janson C, et al. Asthmatic symptoms and indoor levels of micro-organisms and house dust mites. Clin Exp Allergy 1995;25:423-31.

27 UCB Institute of Allergy. European white book on allergy. Brussels: UCB Institute of Allergy, 1997.

28 Gallup J, Kozak P, Cummins L, et al. Indoor mold spore exposure: characteristics of 127 homes in southern California with endogenous mold problems. Experientia Suppl 1987;51:139-42.

29 Rylander R. Airborne (1-->3)-beta-D-glucan and airway disease in a daycare center before and after renovation. Arch Environ Health 1997;52:281-5.

30 Thorn J, Rylander R. Airways inflammation and glucan in a rowhouse area Am J Respir Crit Care Med 1998;157:1798-803.

31 Wan GH, Li CS. Indoor endotoxin and glucan in association with airway inflammation and systemic symptoms. Arch Environ Health 1999;54:172-9.

32 Wessen B, Schoeps KO. Microbial volatile organic compounds - what substances can be found in sick buildings? Analyst 1996;121:1203-5.

33 Wieslander G, Norbäck D, Nordström K, et al. Nasal and ocular symptoms, tear film stability and biomarkers in nasal lavage, in relation to buildingdampness and building design in hospitals. Int Arch Occup Environ Health 1999:72:451-61.

34 Hirvonen MR, Ruotsalainen $M$, Roponen $M$, et al. Nitric oxide and proinflammatory cytokines in nasal lavage fluid associated with symptoms and exposure to moldy building microbes. Am J Respir Crit Care Med 1999;160:1943-6.

35 Wålinder R, Norbäck D, Wieslander G, et al. Acoustic rhinometry and lavage biomarkers in relation to some building characteristics in Swedish schools. Indoor Air 2001;11:2-9.

36 Nordström K, Norbäck D, Wieslander G, et al. The effect of building dampness and type of building on eye, nose, and throat symptoms in Swedish hospitals. J Environ Med 1999;1:127-35.

37 Pirhonen I, Nevalainen A, Husman T, et al. Home dampness, moulds and their influence on respiratory infections and symptoms in adults in Finland. Eur Respir J 1996;9:2618-22.

38 Platt SD, Martin CJ, Hunt SM, et al. Damp housing, mould growth, and symptomatic health state. BMJ 1989;298:1673-8.

39 Dales RE, Burnett $R$, Zwanenburg $H$. Adverse health effects among adults exposed to home dampness and molds. Am Rev Respir Dis 1991;143:505-9.

40 Biörnsson E, Plaschke P, Norrman E, et al. Symptoms related to asthma and chronic bronchitis in three areas of Sweden. Eur Respir J 1994;7:2146-53. 